\title{
Linguagem, currículo e ensino e aprendizagem nas DCE
}

\section{Language, curriculum and teaching and learning in DCE}

\author{
Pascoalina Bailon de Oliveira SALEH ${ }^{1}$ \\ Universidade Estadual de Ponta Grossa
}

Resumo: Este trabalho é um estudo das Diretrizes Curriculares da Educação Básica do Estado do Paraná com o objetivo de investigar qual é a sua concepção de currículo, de ensino e aprendizagem e de linguagem e como essas concepções se articulam no documento. A proposta filia-se às teorias críticas da educação, de cunho marxista, e defende um currículo disciplinar que leve o aluno a compreender que as estruturas sociais são históricas, contraditórias e abertas, condição, segundo ela, para a superação de uma sociedade de classes. Do ponto de vista do processo de ensino e aprendizagem, é possível depreender a sua filiação, ainda que não declarada, ao construtivismo vigotskiano, o qual entende que o sujeito se constitui nas relações sociais. Considera, ainda, partindo de Bakhtin e seu Círculo, que a linguagem, assim como o sujeito, se constitui na interação social, ressaltando-se o seu caráter de atividade discursiva, dialógica bem como o aspecto ideológico a ela inerente. Entretanto, o texto das DCE favorece uma interpretação equivocada das noções de língua, pois não diferencia claramente o culto e o normativo, e de dialogia, uma vez que sugere a sua vinculação às vozes das classes sociais, o que pode comprometer a interpretação da proposta.

Palavras-chave: Diretrizes Curriculares da Educação Básica do Estado do Paraná. Linguagem. Currículo. Ensino e aprendizagem.

Abstract: This work is a study of the Basic Education Curriculum Guidelines of the State of Paraná (DCEs). It investigates the concepts of curriculum, teaching and learning and language within those guidelines and also how these concepts are articulated in the document. The DCEs is guided by critical theories of education, from a Marxist viewpoint, and supports a disciplinary curriculum that leads students to understand that social structures are historical, contradictory and open, making it possible for the overcoming of a class-based society. From the standpoint of teaching and learning, it is possible to infer that the DCE guidelines support, though not explicitly, Vigotskian constructivism, which understands that the subject is defined by social relations. This study also considers, from the starting point of the ideas of Bakhtin and his Circle, that language, as well as the subject is defined by social interaction, emphasising language's character as a discursive activity, dialoguing with the ideological aspect inherent in it. However, the text of the DCE favours an equivocal interpretation of the notions of language and because it does not clearly differentiate between the standard and the normative, and the dialogic, as it suggests its association with the voices of social classes, which can compromise the interpretation of the proposal.

Keywords: Basic Education Curriculum Guidelines of the State of Paraná. Language. Curriculum. Teaching and learning.

\author{
${ }^{1}$ Doutora em \\ Linguística pela \\ UNICAMP - E-mail: \\ <pbosaleh@gmail.com>
}




\section{Introdução}

As Diretrizes Curriculares da Educação Básica do Estado do Paraná, doravante DCE, cuja versão definitiva foi disponibilizada na Página da SEED em 2009², em diversas passagens avalia explicitamente os PCN de forma a ressaltar divergências entre as duas propostas. Embora nosso foco neste trabalho seja a proposta de Língua Portuguesa, essa avaliação é também clara no texto A Educação Básica e a Opção pelo Currículo Disciplinar, que antecede, nos respectivos volumes, todos os documentos das disciplinas específicas, indicando tratar-se de uma posição comum a todos eles.

Com efeito, como o próprio título antecipa, o referido texto critica a concepção de "currículo estruturado com base nas experiências e/ou interesses dos alunos", modelo que daria sustentação à "implementação do projeto neoliberal de educação”, que teria sido difundido pelos PCN. As Diretrizes declaram sua opção por um currículo disciplinar que, segundo o documento, enfatiza a escola como lugar de socialização dos conhecimentos historicamente sistematizados.

Uma vez que, assim como os PCN, as DCE se filiam ao interacionismo, vale a pena verificar em que medida as diretrizes estaduais assumem, ou não, os mesmos pressupostos teóricos que fundamentam os parâmetros nacionais. Diante disso, o objetivo deste trabalho é investigar qual é a concepção de currículo, de ensino e aprendizagem e de linguagem das DCE e como essas concepções se relacionam entre si. A discussão será guiada, em grande parte, pelo diálogo que as DCE travam com os PCN, retomando e ampliando reflexões realizadas em Saleh (2010a).

\section{O currículo e o papel das experiências dos alunos no processo de ensino e aprendizagem}

O texto A Educação Básica e a Opção pelo Currículo Disciplinar situa a visão de currículo adotada pelas DCE, fundamentada, segundo o documento, nas teorias críticas da educação:

Para as teorias críticas, nas quais estas diretrizes se fundamentam, o conceito de contextualização propicia a formação de sujeitos históricos - alunos e professores - que, ao se apropriarem do conhecimento, compreendem que as estruturas sociais são históricas, contraditórias e abertas. É na abordagem dos conteúdos e na escolha dos métodos de ensino advindo das disciplinas curriculares que as inconsistências e as contradições presentes nas estruturas sociais são compreendidas. Essa compreensão se dá num processo de luta política em que estes sujeitos constroem sentidos múltiplos em relação a um objeto, a um acontecimento, a um significado ou a um fenômeno. Assim, podem fazer escolhas e agir em favor de mudanças nas estruturas sociais. (PARANÁ, 2008, p. 30). 
O fragmento acima deixa bastante evidente que o seu autor institucional, o governo do Estado do Paraná à época, entende que a função da escola é propiciar as condições para que os alunos compreendam o funcionamento das estruturas sociais, isto é, suas inconsistências e contradições. Cabe a ela possibilitar que esses sujeitos construam sentidos outros em relação à realidade que os cerca, de forma que possam não só se situar nas estruturas sociais, mas fazer opções e lutar por mudanças.

Trata-se de uma concepção fortemente vinculada à pedagogia histórico-crítica, que vê a educação como mediadora da prática social, a qual, por sua vez, é "o ponto de partida e o ponto de chegada da prática educativa” (SAVIANI, apud PARANÁ, 2008, p. 45). Dessa forma, as DCE adotam para si a finalidade que essa corrente estabelece para a escola, a qual pressupõe que esta esteja articulada com a concepção política socialista, isto é, contribuir "para a superação da sociedade vigente em direção a uma sociedade sem classes”. É o que lemos em Saviani (2008), um de seus mais importantes teóricos. Segundo o autor, nessa perspectiva

[...] procura-se fundar e objetivar historicamente a compreensão da questão escolar, a defesa da especificidade da escola e a importância do trabalho escolar como elemento necessário ao desenvolvimento humano em geral. A escola é, pois, compreendida com base no desenvolvimento histórico da sociedade; assim compreendida, torna-se possível a sua articulação com a superação da sociedade vigente em direção a uma sociedade sem classes, a uma sociedade socialista. É dessa forma que se articula a concepção política socialista com a concepção pedagógica histórico-crítica, ambas fundadas no mesmo conceito geral de realidade, que envolve a compreensão da realidade humana como sendo construída pelos próprios homens, a partir do processo de trabalho, ou seja, da produção das condições materiais ao longo do tempo. (SAVIANI, 2008, p. 103 - nossa ênfase).

Assim, como antecipado na introdução deste trabalho, as DCE deixam claro o seu distanciamento em relação a um currículo estruturado com base nas experiências e/ou interesses dos alunos, modelo que estaria presente na implementação do projeto neoliberal de educação, o qual teria sido difundido nos PCN.

A opção das Diretrizes é por um currículo disciplinar que enfatize a escola como lugar de socialização dos conhecimentos historicamente sistematizados. Por isso, ressaltam a importância dessa função ao afirmar que, para os estudantes de classes menos favorecidas, algumas vezes a escola é a única oportunidade "de acesso ao mundo letrado, do conhecimento científico, da reflexão filosófica e do contato com a arte” (PARANÁ, 2008, p. 14).

Porém, organizar o currículo por disciplina não significa, para as DCE, tratar os conteúdos de forma isolada. Ao contrário, no interior de cada disciplina, eles devem ser tratados de forma contextualizada 
e interdisciplinar, contribuindo tanto "para a crítica às contradições sociais, políticas e econômicas presentes nas estruturas da sociedade contemporânea" (PARANÁ, 2008, p. 14) quanto para que se compreenda a produção científica, a reflexão filosófica e a criação artística não como verdades absolutas, mas na sua relação com os contextos em que elas se constituem.

O documento afirma que a escola deve orientar "para uma aprendizagem específica, colocando em perspectiva o seu aspecto formal e instituído, o qual diz respeito aos conhecimentos historicamente sistematizados e selecionados para compor o currículo escolar” (PARANÁ, 2008, p. 15). Afirma ainda que as disciplinas assim constituídas, embora difiram da abordagem das ciências em que se referenciam, estruturam-se segundo os mesmos princípios epistemológicos e cognitivos dessas ciências, entre os quais são citados os mecanismos conceituais e simbólicos. Em outras palavras, a concepção de currículo adotada, de acordo com o que diz o próprio documento, além de considerar fatores ditos externos - como aqueles determinados pelo regime sociopolítico, religião, família e trabalho, características sociais e culturais do público escolar - e fatores específicos do sistema, como, por exemplo, os níveis de ensino, pretende também valorizar os saberes produzidos pela academia.

Nesse sentido, vale atentar para o fato de que o texto sobre currículo dialoga o tempo todo com os PCN, procurando caracterizá-los como uma proposta que nega os conhecimentos historicamente produzidos em favor das experiências e/ou interesses dos alunos. Essa posição é antecipada pela carta de apresentação do documento, assinada pela Secretária de Educação, Yvelise Freitas de Souza Arco-Verde:

Tais políticas educacionais, estabelecidas no final da década de 1990, alteraram a função da escola ao negligenciar a formação específica do professor e esvaziar as disciplinas de seus conteúdos de ensino, de modo que o acesso à cultura formal ficou mais limitado, principalmente para as camadas socialmente marginalizadas.

Contrapondo-nos a esta concepção, salientamos que, para a maioria da população brasileira, a escola constitui a alternativa concreta de acesso ao saber, entendido como conhecimento socializado e sistematizado na instituição escolar. Sob esta perspectiva de escola pública, construímos essas Diretrizes Curriculares, por meio de uma metodologia que primou pela discussão coletiva ocorrida, efetivamente, durante os últimos cinco anos e envolveu todos os professores da rede ${ }^{3}$. (PARANÁ, 2008).

Os PCNs, como se sabe, teve sua versão final publicada no período a que se refere a Secretária no trecho acima.

Para dar mostras de como tal postura se manifesta nas Diretrizes Curriculares de Língua Portuguesa, retomaremos dois fragmentos do corpo do texto sobre currículo.
${ }^{3}$ Em Saleh (2010a), embora reconhecendo o mérito do esforço da Secretaria de Educação para tentar viabilizar a participação dos professores do Estado do Paraná na elaboração da referida proposta curricular, questionamos o alcance dessa participação, uma vez que ela não reverteu em uma mudança perceptível na prática dos professores. Diante disso, interpretamos a ênfase nessa anunciada contribuição como uma estratégia para inibir possíveis críticas e discordâncias, inclusive da parte dos próprios docentes, em relação ao documento. 
No primeiro são apresentadas críticas à perspectiva experiencial, a qual se centraria no indivíduo e colocaria os saberes acadêmicos em segundo plano, dando, em consequência, lugar ao utilitarismo:

As críticas a esse tipo de currículo referem-se a uma concepção curricular que se fundamenta nas necessidades de desenvolvimento pessoal do indivíduo, em prejuízo da aprendizagem dos conhecimentos histórica e socialmente construídos pela humanidade. Além disso, a perspectiva experiencial reduz a escola ao papel de instituição socializadora, ressaltando os processos psicológicos dos alunos e secundarizando os interesses sociais e os conhecimentos específicos das disciplinas pois considera o ensino dos saberes acadêmicos é (sic) apenas um aspecto, de importância relativa, a ser alcançado. Uma vez que esta concepção de currículo não define o papel das disciplinas escolares na organização do trabalho pedagógico com a experiência, o utilitarismo surge como um jeito de resolver esse problema, aproximando os conteúdos das disciplinas das aplicações sociais possíveis do conhecimento. (PARANÁ, 2008, p. 18).

Esse tipo de currículo, segundo informa as DCE, ecoando as palavras da Secretária Yvelise Freitas de Souza Arco-Verde, está contemplado nas ideias pedagógicas da Escola Nova "e na implementação do projeto neoliberal de educação, difundido no documento chamado Parâmetros Curriculares Nacionais” (PARANÁ, 2008, p. 17) e promove o esvaziamento dos conteúdos disciplinares "para dar destaque aos chamados temas transversais” (PARANÁ, 2008, p. 24).

No segundo trecho, o texto sobre currículo acusa a proposta dos PCN de submeter a escola à ordem capitalista, crítica que também anuncia o tom das DCE específicas de Língua Portuguesa. Para isso vale-se de uma citação de Zotti em que este condena não só a concepção apoiada na experiência e interesses dos alunos, mas igualmente a concepção cientificista de currículo. Segundo o referido autor, as duas visões de currículo

[...] pautam-se em uma visão redentora frente à relação educação e sociedade, com respostas diferenciadas na forma, mas defendendo e articulando um mesmo objetivo - adaptar a escola e o currículo à ordem capitalista, com base nos princípios de ordem, racionalidade e eficiência. Em vista disso, as questões centrais do currículo foram os processos de seleção e organização do conteúdo e das atividades, privilegiando um planejamento rigoroso, baseado em teorias científicas do processo ensino-aprendizagem, ora numa visão psicologizante, ora numa visão empresarial. (ZOTTI apud PARANÁ, 2008, p. 19).

Essas passagens evidenciam, por um lado, a crença manifesta nas DCE de que só é possível abordar os conteúdos de forma rigorosa e crítica nos limites das disciplinas escolares historicamente constituídas; por outro, 
a opção do documento por uma pedagogia de cunho marxista nos permite entender por que a questão ideológica é tão importante para as Diretrizes de Língua Portuguesa. Isso fica bastante evidente quando se defende um ensino que propicie ao aluno "condições de se posicionar criticamente diante de uma sociedade de classes, repleta de conflitos e contradições" (PARANÁ, 2008, p. 66), conforme vimos acima. Voltaremos a essa questão quando formos discutir a concepção de linguagem da proposta.

Antes disso, porém, examinaremos com um pouco mais de detalhe a forma como as DCE veem o papel da experiência no processo de ensino e aprendizagem, um dos pontos centrais das críticas das DCE aos PCN.

Algumas passagens que enfocam o papel do aluno e/ou do professor nesse processo nos permitem entender que lugar as Diretrizes atribuem à experiência na aquisição do conhecimento: "o ensino da nomenclatura gramatical, de definições ou regras a serem construídas, com a mediação do professor, deve ocorrer somente após o aluno ter realizado a experiência de interação com o texto" (PARANÁ, 2008, p. 60-61- nossa ênfase); "ressalta-se que os conhecimentos prévios e o grau de desenvolvimento cognitivo e linguístico dos alunos precisam ser considerados pelo professor na seleção/escolha dos conteúdos específicos a serem trabalhados em sala de aula” (PARANÁ, 2008, p. 62 - nossa ênfase).

Ainda que as DCE não declarem explicitamente, diante de afirmações como essas é possível concluir que há uma clara opção por uma determinada concepção de conhecimento e de sua aquisição, isto é, a sua visão de ensino-aprendizagem também incorpora a ideia de que o aluno deve ser o centro desse processo, tendo seus conhecimentos prévios e seu desenvolvimento cognitivo respeitados. Nessa perspectiva não cabe ao professor transmitir conhecimentos, mas mediar a sua construção pelo aluno, o que, em linhas gerais, caracteriza o construtivismo.

Trata-se, pois, de uma forma de ver a aquisição do conhecimento segundo a qual é o aprendiz que, partindo de sua capacidade e de sua experiência, constrói o seu próprio conhecimento, exercendo, pois, um papel ativo na sua aquisição. Assim, entende-se que o conhecimento é uma construção de natureza histórica e social, para a qual também contribuem fatores de ordem cultural e psicológica. Por isso, o professor deixa de ser a fonte do conhecimento e, consequentemente, do processo de ensino-aprendizagem, como na visão tradicional de ensino, para se tornar um guia, um orientador ou mediador da interação do aprendiz com o objeto a ser conhecido. Correlativamente, o aluno deixa de desempenhar um papel passivo, e, portanto, de receptor, para assumir uma posição ativa e central nesse percurso.

Nesse papel o professor de Língua Portuguesa deve considerar os conhecimentos prévios e o grau de desenvolvimento cognitivo e linguístico 
dos alunos para organizar as atividades visando ao domínio das práticas de linguagem ${ }^{4}$.

Logo após o segundo dos dois fragmentos acima, as DCE apresentam a seção de número 3, intitulada "Conteúdo estruturante". Nela este é assim definido:

Entende-se por Conteúdo Estruturante, em todas as disciplinas, o conjunto de saberes e conhecimentos de grande dimensão, os quais identificam e organizam uma disciplina escolar. A partir dele, advêm os conteúdos a serem trabalhados no dia-a-dia da sala de aula.

A seleção do Conteúdo Estruturante está relacionada com o momento histórico-social. Na disciplina de Língua Portuguesa, assume-se a concepção de linguagem como prática que se efetiva nas diferentes instâncias sociais, sendo assim, o Conteúdo Estruturante da disciplina que atende a essa perspectiva é o discurso como prática social. (PARANÁ, 2008, p. 62-63).

Dessa forma, as DCE estabelecem que o discurso como prática social é o Conteúdo Estruturante de Língua Portuguesa, o que significa dizer que essa disciplina tem como eixo organizador os saberes e conhecimentos necessários à prática de linguagem que se realiza nas diferentes instâncias sociais, entendidos a partir da concepção interacionista.

Como vimos, o conceito de interação mobilizado pelas DCE baseia-se em Bakhtin. Nesse sentido, lembramos que o construtivismo abriga diferentes orientações da psicologia da aprendizagem, entre elas, as formulações de Vygotsky. Parece-nos que é principalmente nesse estudioso que, direta ou indiretamente, as DCE buscaram elementos para costurar a sua concepção de linguagem à de ensino e aprendizagem.

É interessante notar que Bakhtin e Vygotsky nasceram na Rússia bem ao final do século XIX (1895 e 1896) e compartilharam a experiência dos anos revolucionários, embora Vygotsky tenha vivido apenas 38 anos e Bakhtin tenha tido uma vida longa, de 80 anos. Dessa forma, como aponta Freitas (2005), viveram no mesmo contexto histórico e no mesmo ambiente teórico-ideológico, desenvolvendo semelhantes concepções do homem e do mundo. Nesse contexto, abraçaram os ideais do "projeto de uma nova sociedade baseada na organização socialista” (FREITAS, 2005, p. 297). Ainda segundo Freitas (2005), ambos possuíam do marxismo uma visão crítica própria, na medida em que valorizavam a subjetividade e a singularidade, contrapondo-se ao modo mecanicista e burocrático com que o sistema imperava em seu país.

Segundo Freitas (2005), Bakhtin e Vygotsky

construíram uma visão totalizante, não fragmentada da realidade, uma perspectiva que, enraizada na história, compreende o homem como um conjunto de relações sociais (Freitas, 1994a). Contrários às dicotomias

\author{
${ }^{4}$ Nesse sentido \\ as DCE não se \\ distanciam dos \\ PCN, os quais \\ também não fazem \\ referência ao termo \\ construtivismo, \\ mas evidenciam a \\ sua adesão a essa \\ concepção, por \\ exemplo, nessa \\ passagem que \\ resume o papel \\ e a relação dos \\ três elementos \\ envolvidos na \\ prática pedagógica: \\ "os sujeitos \\ se apropriam \\ dos conteúdos, \\ transformando-os \\ em conhecimento \\ próprio, por meio \\ da ação sobre \\ eles, mediada pela \\ interação com o \\ outro" (BRASIL, \\ 1998, p. 34).
}


presentes nas concepções de linguagem e de psicologia por oscilarem entre os pólos subjetivo e o objetivo, arquitetaram suas teorias num entrelaçamento de sujeito e objeto, propondo uma síntese dialética imersa na cultura e na história. (FREITAS, 2005, p. 300).

Dessa forma, Bakhtin critica tanto os sistemas filosófico-linguísticos que veem "a língua como um processo incessante de criação individual (subjetivismo-idealista) como aqueles que a veem como um sistema de formas imutáveis (objetivismo-abstrato)”. Além disso, estende sua análise à psicologia "que, cindida em seus aspectos objetivos e subjetivos, precisa recuperar a dialética do externo e interno" (FREITAS, 2005, p. 300).

Nessa mesma direção, afirma a autora, Vygotsky desenvolve uma psicologia que procura dar conta do homem todo, pois entende que o sujeito não se constitui a partir de fenômenos internos, como querem as psicologias racionalistas, nem se reduz a um mero reflexo passivo do meio, como querem as psicologias empiristas. Distanciando-se de ambas, defende que "o sujeito se constitui na relação" (FREITAS, 2005, p. 300).

A alusão a esse princípio - que é básico em toda proposta que pretende definir como objeto de ensino de língua o discurso enquanto prática social - nos enseja a examinar com mais detalhes a relação que as DCE estabelecem entre linguagem e interação, bem como os desdobramentos conceituais aí implicados.

\section{Linguagem, interação e ideologia nas DCE}

Após apresentar um histórico de como a língua e seu ensino foram concebidos dos primórdios do nosso país até a atualidade, as DCE, coerentemente com as suas críticas à visão de currículo dos PCN, imputam a este documento a desconsideração da dimensão discursiva da linguagem. As DCE lançam mão de uma citação de Brait segundo a qual

[...] as indicações dos PCNs podem ser coerentes e produtivas, e de fato o são em vários aspectos, mas, encerrando o trabalho com o texto em modelos preestabelecidos, afastam-se da proposta do dialogismo bakhtiniano diante do texto, dos discursos, da vida, do conhecimento. (BRAIT apud PARANÁ, 2008, p. 47).

Ainda ancorando-se em Brait, as DCE prosseguem afirmando que essa restrição "impede um trabalho mais aberto e histórico com os textos e seus leitores":

O trabalho com modelos preestabelecidos enfatiza os aspectos formais do texto, deixando de considerar que todo texto é um elo na cadeia da interação social, sempre é uma resposta ativa a outros textos e pressupõe outras respostas. A abordagem apenas formal exclui o texto de seu contexto social. (PARANÁ, 2008, p. 47). 
Mais à frente, procuram explicitar como entendem a linguagem, ressaltando a natureza social desta, conforme se lê abaixo:

As Diretrizes ora propostas assumem uma concepção de linguagem que não se fecha na sua condição de sistema de formas (...) mas abre-se para a "sua condição de atividade e acontecimento social, portanto estratificada pelos valores ideológicos” (RODRIGUES, 2005, p. 156). Nesse sentido, a linguagem é vista como fenômeno social, pois nasce da necessidade de interação (política, social, econômica) entre os homens. (PARANÁ, 2008, p. 49).

Essa citação ressalta o que, de acordo com o documento, fica de fora na abordagem da linguagem quando se assume seja uma perspectiva formal estrita, seja uma perspectiva que, mesmo tomando o texto como unidade de ensino, desconsidera a sua condição de atividade e acontecimento social. As Diretrizes enfatizam o dinamismo e a historicidade dos agentes na interação verbal, processo determinante tanto da "constituição social da linguagem" como dos próprios "sujeitos envolvidos nesse processo" (PARANÁ, 2008, p. 50).

Para entender a especificidade da proposta das DCE e, portanto, a crítica aos PCN segundo a qual, como vimos, esse documento privilegiaria a abordagem formal do texto, parece-nos necessário retomar a questão da ideologia e sua relação com o discurso, a fim de verificar com mais cuidado seu estatuto na formulação das Diretrizes.

Nela, aparecem com frequência o termo ideológico e suas variantes, muitas vezes em contexto em que se chama a atenção para outros vértices da interação humana, tais como o econômico e o político, também implicados na linguagem segundo as DCE e, ao que tudo indica, subsumidos ao social $^{5}$. Esse foco no aspecto ideológico da linguagem está relacionado, como vimos, à filiação das diretrizes à concepção de currículo das teorias críticas da educação.

Também chama a atenção nas Diretrizes a reiteração do sentido de luta e conflito (p. ex. luta/conflito política; luta entre vozes sociais), bem como do conceito de classe (classe social dominante; classes menos favorecidas; classes letradas; classes dirigentes; classes populares; classe social; sociedade de classes). A título de exemplo, trazemos abaixo dois fragmentos:

Dessa forma, será possível a inserção de todos os que frequentam a escola pública em uma sociedade cheia de conflitos sociais, raciais, religiosos e políticos de forma ativa, marcando, assim, suas vozes no contexto em que estiverem inseridos. (PARANÁ, 2008, p. 48 - nossa ênfase).

Cabe, entretanto, reconhecer que a norma padrão, além de variante de prestígio social e de uso das classes dominantes, é fator de agregação social e

\author{
${ }^{5}$ Comparativamente \\ essas palavras \\ aparecem com \\ muito menos \\ frequência nos \\ PCN. Na verdade, \\ salvo engano, os \\ Parâmetros não \\ mencionam uma \\ vez sequer a palavra \\ econômico ou uma \\ de suas cognatas. \\ Ainda nessa direção \\ ressaltamos que os \\ PCN se resumem \\ a fazer algumas \\ poucas referências à \\ classe social.
}


cultural e, portanto, é direito de todos os cidadãos, sendo função da escola possibilitar aos alunos o acesso a essa norma.

[...] É por meio do aprimoramento linguístico que o aluno será capaz de transitar pelas diferentes esferas sociais, usando adequadamente a linguagem tanto em suas relações cotidianas quanto nas relações mais complexas - no dizer de Bakhtin (1992) - e que exigem maior formalidade. Dessa forma, o aluno terá condições de se posicionar criticamente diante de uma sociedade de classes, repleta de conflitos e contradições. (PARANÁ, 2008, p. 66 - nossa ênfase).

Diante disso, a insistência no aspecto ideológico da linguagem é uma das formas pelas quais as DCE procuram marcar seu diferencial em relação aos PCN, como antecipado no texto sobre currículo. Vale notar, então, que as citações diretas do Círculo de Bakhtin sobre a ideologia foram extraídas predominantemente do livro Marxismo e Filosofia da Linguagem, um dos textos do Círculo que procura fazer um diálogo com o marxismo. É bom lembrar que ele foi publicado com a assinatura de Voloshinov, porém mais tarde teve sua autoria atribuída a Bakhtin por alguns estudiosos. Atualmente, no entanto, muitos dos que estudam o legado do Círculo, dentre os quais Faraco $\left(2009^{6}\right)$, entendem que seu autor é de fato Voloshinov. Nesta discussão, porém, exceto em casos das citações, continuaremos a nos referir a Bakhtin/Voloshinov para identificar a autoria desse livro.

Antes de avançarmos no exame do texto das DCE, convém refletirmos um pouco sobre como o Círculo de Bakhtin entende a ideologia. Conforme Faraco (2009) em geral os textos do Círculo usam essa palavra "para designar o universo dos produtos do 'espírito' humano”, isto é, para nomear aquilo que outros autores chamam de "cultura imaterial ou produção espiritual” (FARACO, 2009, p. 46). Ideologia é então o nome dado pelo Círculo ao universo que engloba a arte, a ciência, a filosofia, o direito, a religião, a ética, a política, tomados como conjunto. Quando usada no plural, designa a pluralidade das esferas da produção imaterial. Nesse sentido, a arte, a ciência, o direito, a religião, a ética, a política são, pois, as ideologias, as quais dizem respeito às áreas da atividade intelectual humana.

Assim, nos textos do Círculo de Bakhtin esses termos não possuem o sentido negativo de “ocultamento" ou “mascaramento do real”, comum em algumas vertentes marxistas (FARACO, 2009). A ideologia é vista como "expressão de uma tomada de posição determinada” (MIOTELLO, 2008, p. 169) e, portanto, como um espaço de contradição.

Conforme lembra Faraco (2009), no livro Marxismo e filosofia da linguagem Bakhtin/Voloshinov afirma que

tudo que é ideológico (isto é - entenda-se bem, todos os produtos da cultura dita imaterial) possui significado; é, portanto, um signo. E conclui com a

\author{
${ }^{6}$ Faraco é uma \\ importante \\ referência para as \\ DCE, especialmente \\ o livro Linguagem \\ \& diálogo: as idéias \\ linguísticas do \\ Círculo de Bakhtin, \\ em sua edição de \\ 2003. A edição que \\ nós utilizamos é de \\ 2009.
}


afirmação de que 'sem signos não existe ideologia. [...], querendo com isso dizer que o universo da criação ideológica é fundamentalmente de natureza semiótica [...]. (FARACO, 2009, p. 47).

Além disso, para o Círculo a significação dos signos envolve necessariamente uma dimensão axiológica, isto é, avaliativa ou valorativa, por isso nossa relação com o mundo é sempre atravessada por valores (FARACO, 2009). Dessa forma,

[...] a significação dos enunciados tem sempre uma dimensão avaliativa, expressa sempre um posicionamento social valorativo. Desse modo qualquer enunciado é, na concepção do Círculo, sempre ideológico - para eles não existe enunciado não-ideológico. E ideológico em dois sentidos: qualquer enunciado se dá na esfera de uma das ideologias (i.e., no interior de uma das áreas da atividade intelectual humana) e expressa sempre uma posição avaliativa (i.e., não há enunciado neutro; a própria retórica da neutralidade é também uma posição axiológica). (FARACO, 2009, p. 47).

As Diretrizes lançam mão de uma das passagens mais citadas para se referir à forma como o autor do livro situa a relação entre a linguagem e a ideologia. Bakhtin/Voloshinov define a palavra como um tecido de fios ideológicos e como "uma arena em miniatura onde se entrecruzam e lutam os valores sociais de orientação contraditória":

As palavras estão carregadas de conteúdo ideológico, elas "são tecidas a partir de uma multidão de fios ideológicos e servem de trama a todas as relações sociais em todos os domínios”. (BAKHTIN/VOLOCHINOV, 1999, p. 41).

Sob essa perspectiva, o ensino-aprendizagem de Língua Portuguesa visa aprimorar os conhecimentos linguísticos e discursivos dos alunos, para que eles possam compreender os discursos que os cercam e terem (sic!) condições de interagir com esses discursos. Para isso, é relevante que a língua seja percebida como uma arena em que diversas vozes sociais se defrontam, manifestando diferentes opiniões. A esse respeito, Bakhtin/Voloshinov (1999, p. 66) defende: ' (...) cada palavra se apresenta como uma arena em miniatura onde se entrecruzam e lutam os valores sociais de orientação contraditória. A palavra revela-se, no momento de sua expressão, como produto de relação viva das forças sociais'. (PARANÁ, 2008, p. 50).

As DCE sugerem haver uma estreita relação entre vozes sociais, ideologia e discurso. Na verdade, em algumas passagens, como a primeira abaixo, a expressão vozes sociais e o termo ideologias são tomados como se referindo a uma mesma realidade; em outras, como se lê na segunda, há realidades próximas, mas distintas, que dizem respeito ao discurso ou à dimensão discursiva:

Nessa perspectiva, o texto não serve apenas para o aluno identificar, por exemplo, os adjetivos e classificá-los; considera-se que o texto tem o que 
dizer, há ideologias, vozes [sociais], e para atingir a sua intenção, utiliza-se de vários recursos que a língua possibilita. (PARANÁ, 2008, p. 79 - nossa ênfase).

É nessa dimensão dialógica, discursiva que a leitura deve ser experienciada, desde a alfabetização. O reconhecimento das vozes sociais e das ideologias presentes no discurso, tomadas nas teorizações de Bakhtin, ajudam na construção de sentido de um texto e na compreensão das relações de poder a ele inerentes. (PARANÁ, 2008, p. 57 - nossa ênfase).

Então, o que é o discurso? As DCE afirmam que

o uso da língua efetua-se em forma de enunciados, uma vez que o discurso também só existe na forma de enunciados. O discurso é produzido por um "eu”, um sujeito que é responsável por aquilo que fala e/ou escreve. A localização geográfica, temporal, social, etária também são elementos essenciais na constituição dos discursos. (PARANÁ, 2008, p. 63).

Discurso, então, diz respeito à língua em uso e pressupõe a responsabilidade daquele que o produz. Ainda segundo as Diretrizes, "é efeito de sentidos entre interlocutores, não é individual, ou seja, não é um fim em si mesmo, mas tem sua gênese sempre numa atitude responsiva a outros textos (BAKHTIN, 1999)”. (PARANÁ, 2008, p. 63). O documento prossegue afirmando que entende o discurso como "resultado da interação - oral ou escrita - entre sujeitos, é 'a língua em sua integridade concreta e viva'” (BAKHTIN, apud, PARANÁ, 2008, p. 63); é ainda "toda a atividade comunicativa entre interlocutores” (PARANÁ, 2008, p. 63).

Isso significa que o texto não envolve apenas a formalização do discurso verbal ou não verbal, mas igualmente as condições de produção e de sua elaboração assim como a leitura ou a resposta ativa, constituindo-se como "articulação de discursos, vozes que se materializam, ato humano (...) linguagem em uso efetivo”. (PARANÁ, 2008, p. 51).

Nesse contexto, os gêneros discursivos são definidos, a partir de Bakhtin, como os "tipos relativamente estáveis de enunciados". Trata-se de "formas comunicativas que não são adquiridas em manuais, mas sim nos processos interativos” (MACHADO, 2005, apud PARANÁ, 2009, p. 53). Nessa concepção, antes de o gênero constituir um conceito, é uma prática social e deve orientar a ação pedagógica com a língua. Segundo o documento, compreender essa relação é fundamental para que não se caia tão somente na normatização do gênero e, consequentemente, no que Rojo (2004 apud PARANÁ, 2008, p. 53) define como "pedagogia transmissiva das análises estruturais e gramaticais", que dissocia o texto de sua realidade social.

Os gêneros estão diretamente relacionados à "esfera de atividades em que eles se constituem e atuam, aí implicadas as condições de produção, de 
circulação e recepção" (BRAIT apud PARANÁ, 2008) e potencialmente "são adaptados, transformados, renovados, multiplicados ou até mesmo criados a partir da necessidade que o homem tem de se comunicar com o outro, tendo em vista que "todos os diversos campos da atividade humana estão ligados ao uso da linguagem” (BAKHTIN apud PARANÁ, 2008).

Assumir que os gêneros são flexíveis implica que os textos não estão aprisionados em determinadas propriedades formais, ao contrário do que, segundo as próprias DCE, entendem os $\mathrm{PCN}^{7}$. A opção pela noção de gênero discursivo, diferentemente dos PCN, que adotam a de gênero textual, marca essa diferenciação.

Voltemos ao conceito de discurso. Como vimos acima, as Diretrizes sugerem haver uma estreita relação entre discurso, vozes sociais e ideologia. Um dos fragmentos apresentados acima remete à dimensão dialógica da linguagem. Voltemo-nos então ao conceito de dialogia, procurando entender como ele se relaciona com o conceito de discurso e qual o seu papel na articulação da proposta das Diretrizes.

Estas afirmam que o texto "lança seus sentidos no diálogo intertextual, ou seja, o texto é sempre uma atitude responsiva a outros textos" (PARANÁ, 2008, p. 51), estabelecendo, desse modo, relações dialógicas. Para dar maior precisão ao conceito de diálogo e evitar que ele seja entendido no sentido restrito de comunicação face a face em voz alta, as DCE inserem uma nota de rodapé na palavra diálogo. Essa nota é uma citação de Faraco, na qual o autor afirma que o diálogo deve ser entendido no sentido amplo do termo, 'o simpósio universal', e ainda como "um vasto espaço de luta entre as vozes sociais", "uma espécie de guerra dos discursos” (FARACO, 2003 apud PARANÁ, 2008, p. 51), estabelecido a partir de qualquer materialidade semiótica:

Para haver relações dialógicas, é preciso que qualquer material linguístico (ou de qualquer outra materialidade semiótica) tenha entrado na esfera do discurso, tenha sido transformado num enunciado, tenha fixado a posição de um sujeito social. Só assim é possível responder (em sentido amplo e não apenas empírico do termo), isto é, fazer réplicas ao dito, confrontar posições, dar acolhida fervorosa à palavra do outro, confirmá-la ou rejeitá-la, buscar-lhe um sentido profundo, ampliá-la. Em suma, estabelecer com a palavra de outrem relações de sentido de determinada espécie, isto é, relações que geram significado responsivamente a partir do encontro de posições avaliativas. (FARACO apud PARANÁ, 2008, p. 51).

Dessa forma, as DCE ressaltam o caráter heterogêneo de todo e qualquer enunciado, inclusive os não verbais, uma vez que eles necessariamente trazem em si uma multidão de vozes sociais, a partir das quais o sujeito se (re)constitui discursivamente.

${ }^{7}$ De fato, embora reconheçam a mobilidade dos gêneros, tanto em termos de mudanças históricas, como de surgimento de novos gêneros, os PCN não exploram essa característica, o que fica bastante claro nas sessões dedicadas às indicações metodológicas. 
O documento esforça-se, pois, por costurar uma concepção de linguagem na qual o aspecto ideológico ocupe uma posição central ${ }^{8}$. Para as Diretrizes, a relação de um texto com outros textos é necessariamente de caráter ideológico, de disputa de poder. Por isso, não é suficiente reconhecer a presença de outros textos em um texto que os sucede no tempo, ou mesmo que lhes seja contemporâneo. Considerado na dimensão discursiva, é preciso reconhecer as vozes sociais, os sentidos que nele lutam entre si, numa guerra para fixar sentidos em consonância com posições ideológicas demarcadas.

Sem pretender esgotar descontinuidades conceituais do documento, chamaremos a atenção para dois aspectos da sua formulação.

Primeiro, apesar das críticas à tradição do ensino de língua materna e a assunção de um ensino centrado nas práticas discursivas, as DCE não conseguiram efetivamente situar o lugar da norma padrão na sua proposta. O documento toma as expressões norma padrão e norma culta como sinônimas não em função de uma flutuação terminológica, mas porque não diferencia claramente o normativo e o culto. Em Saleh (2010b) já havíamos identificado essa dificuldade em uma versão anterior do documento, mas a passagem abaixo dá mostras de que essa confusão permaneceu em sua versão definitiva:

Com relação à literatura, até meados do século XX, o principal instrumento do trabalho pedagógico eram as antologias literárias, com base nos cânones. A leitura do texto literário, no ensino primário e ginasial, visava transmitir a norma culta da língua, com base em exercícios gramaticais e estratégias para incutir valores religiosos, morais e cívicos. O objetivo era despertar o sentimento nacionalista e formar cidadãos respeitadores da ordem estabelecida. (PARANÁ, 2008, p. 45 - nossa ênfase).

Com efeito, desconsidera-se o que está implícito nas próprias informações apresentadas, já que um ensino de língua baseado em antologia de clássicos e em exercícios gramaticais, numa época em que a visão gramatical que chegava à escola era essencialmente normativa, não poderia "transmitir a norma culta da língua", no sentido de "registro socialmente valorizado da língua", como lemos na seguinte passagem:

O trabalho com os gêneros, portanto, deverá levar em conta que a língua é instrumento de poder e que o acesso ao poder, ou sua crítica, é legítimo e é direito para todos os cidadãos. Para que isto se concretize, o estudante precisa conhecer e ampliar o uso dos registros socialmente valorizados da língua, como a norma culta. (PARANÁ, 2008, p. 53 - nossa ênfase).

Consequentemente, embora, como mostra o fragmento a seguir, condene o normativismo e reconheça os limites da gramática normativa quando se trata de dar conta do discurso como objeto de ensino, corre-se

${ }^{8}$ Diante do exposto acima, é possível entender melhor o teor da crítica que as DCE fazem aos PCN. Os PCN se restringem a reconhecer, por um lado, a relação constitutiva de um texto com outros textos que o antecederam e, por outro, as posições ideológicas a ele subjacentes, mas sem relacionar esses dois aspectos de forma indissociável. A questão ideológica não é enfatizada nas seções dedicadas à fundamentação teórica do documento, o que prejudica a compreensão do caráter ideológico da linguagem. Assim, embora consideremos discutível afirmar que os PCN restringem a abordagem do texto ao trabalho com o aspecto formal, parece-nos de fato pertinente dizer que tais Parâmetros deixam de enfatizar que "todo texto é um elo na cadeia da interação social”, que ele é sempre "uma resposta ativa a outros textos e pressupõe outras respostas", não propriamente excluindo o contexto social, como afirmam as DCE, mas dando a ele um alcance muito menos significativo do que as Diretrizes preconizam. 
o risco de o interlocutor do documento tomar como problemático apenas o fato de essa gramática 1 - dar mais importância à escrita que à fala; 2 restringir-se à esfera da frase:

A atitude normativista fundamenta-se em teorias que têm pouco a dizer sobre a noção de discurso, porque trabalha com frases ou palavras isoladas do contexto de atividade humana, local de sua gênese. A ênfase na norma gramatical e na historiografia literária decorre de uma mesma concepção de Língua e Literatura, identificada já no Renascimento. Tratou-se de um período de ruptura definitiva entre a escrita e a oralidade (a invenção da imprensa consolidou a supremacia da escrita, como se ela fosse a língua, reforçando ainda mais a língua como instrumento de poder). Além disso, a visão de literatura baseava-se no conceito de modelo originado da pedagogia greco-latina, que buscava moldar o educando a uma realidade ideal encontrada nos clássicos da literatura (FREDERICO \& OSAKABE, 2004). (PARANÁ, 2008, p. 49).

Notemos que é a esse mesmo ensino que as Diretrizes se referem quando afirmam que a leitura do texto literário na escola visava transmitir a norma culta da língua, conforme procuramos mostrar acima.

O segundo aspecto para o qual chamamos a atenção é para o fato de que, em função da ideia assumida pelo documento de que a sociedade é dividida em classes sociais que lutam entre si, pode-se estabelecer uma confusão a respeito da noção de dialogia. É o que as seguintes passagens nos parecem indicar:

É nesse processo de luta política que os sujeitos em contexto de escolarização definem os seus conceitos, valores e convicções advindos das classes sociais e das estruturas político-culturais em confronto. (PARANÁ, 2008, p. 30).

É por meio do aprimoramento linguístico que o aluno será capaz de transitar pelas diferentes esferas sociais, usando adequadamente a linguagem tanto em suas relações cotidianas quanto nas relações mais complexas - no dizer de Bakhtin (1992) - e que exigem maior formalidade. Dessa forma, o aluno terá condições de se posicionar criticamente diante de uma sociedade de classes, repleta de conflitos e contradições. (PARANÁ, 2008, p. 66).

Como a noção de dialogia supõe a ideia de luta entre as diferentes vozes sociais, isso pode levar à conclusão de que estas estão diretamente vinculadas às classes sociais. Nesse sentido, essa luta levaria à superação das contradições sociais ${ }^{9}$ e, portanto, da natureza dialógica da linguagem. Tal posição não está dissociada da acusação que o documento faz aos PCN de adotar uma concepção neoliberal de educação.

Porém, segundo Faraco, autor fundamental na formulação das Diretrizes, a correlação entre vozes e classes sociais é feita por Voloshinov em Marxismo e Filosofia da Linguagem, mas não por Bakhtin, para quem a noção de dialogia é bem mais ampla:

${ }^{9}$ Objetivo maior da perspectiva histórico-crítica em educação, de filiação marxista (Cf. SAVIANI, 2008), a qual, como vimos, fundamenta a visão de currículo adotada pelas DCE. 


\begin{abstract}
Mesmo reconhecendo os jogos de poder, Bakhtin - diferentemente de Voloshinov - não estabelece em nenhum momento uma vinculação estreita entre vozes sociais e classes sociais. Há, sim, no conceitual do plurilinguismo dialogizado, luta social entre as diferentes 'verdades sociais', mas não uma correlação estreita entre essas lutas e a chamada luta de classes. (FARACO, 2009, p. 70).
\end{abstract}

Ou seja, por se tratar de uma luta entre as diferentes "verdades sociais” (FARACO, 2009, p. 70 - aspas do autor), não há no horizonte de Bakhtin a possibilidade de monologização da linguagem.

Isso pode explicar por que, embora fazendo referências ao Círculo de Bakhtin e ao próprio Bakhtin, as formulações das DCE têm apoio predominantemente no livro Marxismo e Filosofia da Linguagem, especialmente as que se referem à questão da ideologia. A brecha para uma vinculação da dialogia às classes sociais e destas à ideologia pode comprometer a clareza não só do conceito de dialogia, mas de toda a proposta.

\title{
Considerações finais
}

As DCE de Língua Portuguesa, como vimos, se filiam às correntes críticas de educação. Dessa forma assumem que os sujeitos são historicamente constituídos e que cabe à escola levar o aluno a compreender, a partir de uma organização curricular disciplinar, que as estruturas sociais são históricas, contraditórias e abertas (PARANÁ, 2008, p. 30), condição para a superação de uma sociedade de classes.

Essa opção apresenta-se como uma resposta àquilo que as DCE consideram o braço curricular da política neoliberal que fundamentaria os PCN, o qual se basearia nas experiências e interesses dos alunos e negaria a especificidade das disciplinas, levando-as ao esvaziamento.

Cabe, no entanto, indagar se a ênfase nas disciplinas escolares historicamente constituídas, e a consequente negação dos temas transversais, não adviria de uma visão reducionista justamente da história, uma vez que, por um lado, frequentemente surgem novos campos de estudos científicos; por outro, a abordagem de certos "conteúdos" é também frequentemente matéria de mais de um desses campos. Um dos motivos que nos levam a essa indagação é, como vimos, a dificuldade do documento para definir o lugar da norma padrão na sua proposta, e a consequente ausência de uma clara diferenciação entre o normativo e o culto. Nesse sentido, ainda que se afirme valorizar os saberes produzidos pela academia, parece que garantir a especificidade histórica da disciplina Língua Portuguesa implicaria garantir o lugar que a gramática normativa vem ocupando na escola e na sociedade.

Do ponto de vista do processo de ensino e aprendizagem, as Diretrizes assumem que o sujeito se constitui nas relações sociais e entende 
que a seleção dos conteúdos específicos a serem trabalhados pelo professor, a quem cabe mediar a construção pelo aluno do conhecimento sobre a linguagem, deve ser norteada pelos conhecimentos prévios e pelo grau de desenvolvimento cognitivo e linguístico dos alunos, o que, em linhas gerais, é compatível com a perspectiva construtivista de aquisição do conhecimento.

Quanto à linguagem, parte-se do princípio de que esta, assim como o sujeito, se constitui na interação, ressaltando-se o seu caráter de atividade discursiva e o aspecto ideológico a ela inerente. Nesse contexto, o discurso é tomado como efeito de sentidos entre interlocutores, cuja gênese se dá sempre numa atitude responsiva a outros textos, revelando a língua em sua integridade concreta e viva. Como já salientamos, dentre outros aspectos que merecem atenção e dos quais não nos ocupamos aqui, fica por redefinir o lugar da norma padrão nesse contexto teórico, já que ela não é claramente diferenciada do uso culto da língua, assim como da noção de dialogia, uma vez que o documento favorece uma interpretação equivocada dela, sugerindo sua vinculação às vozes das classes sociais. Nesse sentido, como procuramos apontar, a instrumentalização dos alunos menos favorecidos para fazerem valer suas vozes na sociedade redundaria na superação das contradições sociais e, portanto, na natureza dialógica da linguagem, algo incompatível com o pensamento bakhtiniano.

Para finalizar, mas deixar aberto o debate, não poderíamos deixar de dizer que essa questão traz outra à tona. Apesar da ainda evidente estratificação e injustiça social no Paraná (e no Brasil), nos cabe perguntar qual é a possibilidade de identificação dos envolvidos no processo educacional com essa proposta. Afinal, não é possível ignorar a diluição da capacidade integradora da classe social como bandeira identitária em decorrência do avanço do capitalismo em níveis mundiais e o consequente deslocamento das preocupações para a "defesa de causas atuais relacionadas a grupos ou categorias” (BAUMAN 2005). Entre essas causas encontram-se aquelas que envolvem as questões de raça, gênero e sexualidade, já incluídas na agenda da educação no Brasil, mas praticamente silenciadas pelas DCE de Língua Portuguesa. Se, por um lado, é preciso, como afirma Bauman (2005), recolocar os aspectos econômicos das diferenças sociais na ordem do dia, por outro, acreditamos que atualmente isso exige um diálogo explícito com as atuais causas identitárias.

\section{Referências}

BAUMAN, Zygmunt. (2005). Identidade: entrevista a Benedetto Vecchi/ Zygmunt Bauman; tradução: Carlos Alberto Medeiros. Rio de Janeiro: Jorge Zahar Ed., 2005. 
BRASIL. Secretaria de Educação Fundamental. Parâmetros curriculares nacionais: terceiro e quarto ciclos - língua portuguesa. Secretaria de Educação Fundamental. Brasília, MEC/SEF, 1998.

FARACO, Carlos Alberto. Linguagem \& diálogo: as idéias linguísticas do Círculo de Bakhtin. Curitiba: Criar, 2003.

. Linguagem \& diálogo: as ideias linguísticas do Círculo de Bakhtin. São Paulo: Parábola Editorial, 2009.

FREITAS, Maria Tereza. A. Nos textos de Bakhtin e Vygotsky: um encontro possível. In: BRAIT, Beth (org.). Bakhtin, dialogismo e construção do sentido. 2 ed. Campinas: Editora da UNICAMP, 2005. p. 295-314

MIOTELLO, Valdemir. Ideologia. In: BRAIT, Beth (org.). Bakhtin: conceitos-chave. 4 ed. São Paulo: Contexto, 2008. p. 167-176

PARANÁ. SEED. Diretrizes Curriculares de Língua Portuguesa para os Anos Finais do Ensino Fundamental e Médio. Curitiba: SEED, 2009. Disponível em http://www.diaadiaeducacao.pr.gov.br/diaadia/diadia/arquivos/File/diretrizes_2009/portugues.pdf. Acesso em: 10 out. 2011.

SALEH, Pascoalina Bailon de Oliveira. Prática Pedagógica IV: fundamentos teóricos e metodológicos dos PCN e DCE da língua portuguesa. Ponta Grossa: UEPG/NUTEAD, 2010a.

Variação e texto nas DCE's do Paraná: algumas implicações para a formação de professores. In: SALEH, Pascoalina Bailon de Oliveira; OLIVEIRA, Silvana (org.). Linguagem, texto e ensino: discussões do CELLIP. Ponta Grossa: Editora UEPG, 2010b. p. 65-76.

SAVIANI, Dermeval. Pedagogia histórico-crítica: primeiras aproximações. 10. ed. rev. Campinas: Autores Associados, 2008. 